\title{
Patient group directions: The application and integration of knowledge in advancing nursing practice
}

\author{
Martin Christensen * \\ Queensland University of Technology, Brisbane, Australia
}

Received: August 10, 2014

Accepted: November 23, 2014 Online Published: December 3, 2014

DOI: $10.5430 /$ jnep.v5n2p103

URL: http://dx.doi.org/10.5430/jnep.v5n2p103

\begin{abstract}
Background: The introduction of Patient Group Directions (PGD) has changed significantly the way in which nurses can now administer prescription only medicines as a one-off for patients requiring this level of service. PGD's are a written authority to administer drugs to patients that are not identified at the time of treatment.

Aim: The aim of this project was to develop a PGD for use within an Outreach team to administer colloid boluses to patients presenting with hypovolemia.

Method: Using a case exemplar this paper will discuss the development of a PGD using aspects of transitional change theory to highlight the potential barriers that were encountered.

Implications for Practice: The implications for this PGD are wide reaching. First it now enables members from the nursing Outreach team to administer colloid fluid boluses to a prescribed patient cohort without the need for prescription. Second, it ensures the deteriorating patient has interventions initiated in a timely and appropriate manner to reduce inadvertent admission to high care areas. Last, it will improve inter-professional team-working and communication so much so that collaborative patient care reduces health costs and identifies earlier those patients requiring substantially greater nursing and medical input.

Conclusion: The experience of developing a working PGD for fluid administration has meant that the Outreach team is able to respond to patients in a more effective way. In addition, it is the experience of developing this PGD that has enabled the team to contemplate other PGD's in the execution of Outreach work.
\end{abstract}

Key Words: Patient group directions, Outreach, Change theory

\section{Introduction}

With the inception of Outreach, unwarranted or inappropriate admissions to the Intensive Care Unit (ICU) have seen a dramatic decrease leaving these valuable beds to those patients who require this form of specialised nursing and medical care. Outreach to the uninitiated is a group of specially trained ICU nurses that provide expert nursing care, education and assistance to patients, fellow nurses and doctors in general ward environments. Developed as a result of the United Kingdom's (UK) Department of Health (DoH) Comprehensive Critical Care ${ }^{[1]}$ white paper, Outreach teams have become important in detecting and managing the deteriorating patient. In addition, Outreach teams are well placed to support those patients discharged to the ward from

*Correspondence: Martin Christensen; Email: mchristensen64@yahoo.com; Address: Queensland University of Technology, Brisbane, Australia. 
high care areas, such as the ICU, so that these patients are treated and managed in a more timely and appropriate manner and thus prevent unnecessary ICU readmission. Despite, having expert physical assessment and communication skills, the Outreach team are hampered by their level of responsibility within the health professional team in terms of drug and fluid administration. Using a patient case exemplar this paper will explore and reflect upon the process of developing and writing a Patient Group Direction (PGD). In particular it will identify the rationale as to the need for a PGD, in this instance combining with this the underlining pathophysiology and pharmacology inherent in its development. It will also give consideration to the legal, ethical and professional issues involved in the administration of prescription only medicines and finally give thought to the implications for practice.

\subsection{Patient case exemplar}

Mrs Jones (not her real name to protect confidentiality), was admitted for elective surgery for the freeing of abdominal adhesions. Her surgery and subsequent short term recovery were uneventful. However, day two post-operatively her vital signs had changed significantly. An Outreach review was requested by the nurse caring for Mrs Jones, asking for an evaluation of her current condition and to support the junior doctor as the latter was unsure what to do. Obtaining a brief handover from Mrs Jones' nurse, it was reported that her current blood pressure was $85-90 \mathrm{mmHg}$ systolic and had been for the last 4 hours. It had also been reported the her urine output had "tailed off" to less than the recommended $\frac{1}{2} \mathrm{ml} / \mathrm{kg} /$ hour $^{[2]}$ and that her total urine output for the last six hours was 70 millilitres. The Outreach nurse's immediate impression of her was someone who was tachypneic, pale and clammy. Closer examination revealed that she had a heart rate of 110 beats per minute with no ectopy, a blood pressure (BP) of 91/34, a non-discernable jugular venous pressure (JVP), and a capillary refill time of more than three seconds. She also had a non-monitored central venous pressure (CVP) line. Mrs Jones also appeared to have lower limb pitting oedema which needed assessment to ascertain if this was due to heart failure or as a result of the surgery. Her previous medical history revealed no cardiac problems and in view of the fact that her JVP and diastolic were low it was decided this was a fluid deficit problem. To confirm this, the Outreach nurse set up a fluid manometer to measure her CVP to find the reading being $3 \mathrm{cms} / \mathrm{H} 2 \mathrm{O}$. It was evident from her prescription chart that Mrs Jones had received 4 litres of crystalloid intravenous (IV) fluids since her return from theatre; the current infusion being one litre of 5\% dextrose running over 8 hours. Yet, it would appear that the fluid given was simply 'third-spacing' (interstitial space fluid trapping) which was probably heightened by a systemic inflammatory response from the recent surgery. Indeed her lab work confirmed this with a "normal' serum sodium in that the hypovolemia wasn't as a re- sult of fluid depletion. Therefore what she needed was a fluid challenge, such as could be done with Gelofusine - an iso-oncotic gelatine solution, ${ }^{[3]}$ that would draw fluid back into the intravascular space and improve her BP. The junior doctor was approached and after conveying their assessment findings the Outreach nurse suggested that Mrs Jones be administered $500 \mathrm{mls}$ of Gelofusine over an hour to see if it would improve her BP. This being a new rotation, the doctor was rather reluctant to prescribe the Gelofusine because she was unfamiliar with its use and instead opted for another bag of crystalloid this time $0.9 \%$ saline until she could confer with her registrar.

The case study highlighted above prompted discussion amongst Outreach nursing colleagues that we were finding it increasingly frustrating not being able to provide a fully rounded Outreach service. ${ }^{[4]}$ One key aspect of this was not being able to administer IV fluids without first having it prescribed because of restrictions for nurses to prescribe under the Medicines Act 1968. ${ }^{[5]}$ This was even more frustrating despite the fact that we had all attended the Acute Life Threatening Events Recognition and Treatment (ALERT) course which advocates in certain conditions the administration of crystalloid or colloid fluids. Therefore, as a result we were reliant on medical staff to prescribe the necessary IV fluids for our patients, which was not always possible in busy ward environments. As a team it was evident we needed to be able to administer colloids legally without the need of a prescription, save all of us attending a nationally recognised nurse prescribing course.

\subsection{Background to the Inception of PGD's}

Nurse prescribing in the UK has now been given the right to prescribe from the entire British National Formulary (BNF) - a pharmaceutical reference used by health professionals which provides advice on medicinal prescribing and pharmacology. Prior to this nurse's were only able to prescribe a limited formulary as deemed appropriate by the Cumberledge ${ }^{[6]}$ and Crown Reports. ${ }^{[7]}$ It was these reports that led to limited prescribing with the introduction of the Medicinal Products: Prescriptions by Nurses Act ${ }^{[8]}$ which saw designated district nurses and health visitors being able to prescribe wound dressings and drugs available on general sale lists. 1994 saw the first Nurse Prescriber's Formulary; however it was the second Crown Report ${ }^{[9]}$ that heralded the introduction of Patient Group Directions (PGD's). Final amendments to the report not only identified new categories of prescriber's but together with the National Health Service Executive Health Service Circular ${ }^{[10]}$ were guidelines for PGD use and implementation acknowledged. This meant that there now existed a legal framework for which nurses could prescribe albeit limitedly. By definition, PGD's are written instructions that allow for the supply, sale and administration of named medicines to individuals that are unidentified at the time of treatment for a specific clinical 
situation without the need for a prescription. ${ }^{[1-14]}$

PGD's are currently used in a wide arena of care delivery situations - from midwifery practice ${ }^{[15]}$ to mental health nursing. ${ }^{[16]}$ It appears from the literature that their main use is in the emergency department ${ }^{[17]}$ or community practices where “one off" drug dispensing is seen as more appropriate in certain situations, for example the administration of the morning after contraceptive pill or the influenza vaccine. Needless to say the development of PGD's has to some degree enable nurses to administer prescription only medicines in situations of necessity. ${ }^{[18]}$ However, the acceptance of using PGD's in the acute setting has not been forthcoming as would be expected.

\subsection{Identifying the need for a PGD in fluid admin- istration}

In the situation described in the case exemplar, PGD's could be very useful when meeting the needs of patients that require immediate action as would be seen with an Outreach referral. The legal framework to be able to prescribe and administer Gelofusine in the form of a PGD, then allowed us to start developing a PGD for fluid administration. It was common knowledge that the Accident and Emergency (A\&E) department were using PGD's to administer certain medicines to patients that required a one-off treatment such as the morning after pill, so it was a case of networking and liaising with those key individuals as to how to proceed. Initial meetings with the PGD development team from A\&E identified that the hospital had an already recognised proforma which meant that the legal authorisation was already established. However, we were mindful of the work undertaken by Robson et al. ${ }^{[19]}$ in developing a PGD for fluid management in an orthopaedic ward for post-operative hypotension. They experienced the same problems as we had in accessing medical staff to review and prescribe fluids. In order to demonstrate success of the PGD, a pilot study of 14 patients who met the inclusion criteria (major joint replacement surgery) were administered $500 \mathrm{mls}$ of $0.9 \%$ normal saline fluid boluses for hypotension. $95 \%$ of patients responded favourably to the boluses with significant increases in blood pressure in addition to suffering no complications as a result of these fluid boluses. This study also found the mean rise in blood pressure was $18.7 \mathrm{mmHg}$ after the first fluid bolus with another $3 \%$ rise following a second fluid challenge $(p<.001)$. Based on pilot study results we were able to support our need for a fluid PGD and as such it was a case of preliminary filling in the key features of the document in collaboration with the ICU pharmacist. Included in the documentation were the drug details, the clinical condition related to the use of Gelofusine, staff characteristics, hospital authorisation and subsequent arrangements for referral before submitting the draft for approval from the clinical governance committee.

\section{Gelofusine}

Gelofusine is a collagen based synthetic plasma volume expander ${ }^{[3]}$ made by the succinylation of gelatine and works by increasing the plasma colloid osmotic pressure. It has a molecular weight of 35,000 Daltons which means it has a similar molecular structure to that of human albumin and also as a result of the succinylation process has a negative charge which prevents leakage into the interstitial space and aids effective colloid osmotic pressure through the Donnan Equilibrium effect. ${ }^{[20,21]}$ Normal colloid osmotic pressure (normal pressure being $28 \mathrm{mmHg}$ ) is maintained within the intravascular space because of dissolved plasma proteins namely albumin. Albumin exerts its osmotic effect not so much by its molecular mass but by the number of molecules present - in essence setting up a solute concentration gradient between the intravascular and interstitial spaces. ${ }^{[20]}$ However, this alone does not solely contribute to the movement of water. The Donnan Equilibrium effect adds a further $50 \%$ to the 'osmotic pull' with the use of sodium. Because of its negative charge, albumin attracts a sodium molecule near to it to maintain electrical neutrality, therefore the presence of the sodium molecule further increases the movement of water. Gelofusine acts in exactly the same way because of its negative charge and the number of molecules present within the intravascular space. ${ }^{[20]}$

Gelofusine is effective in a variety of conditions that require fluid resuscitation, for example, burns, hypovolemic shock, sepsis and haemorrhage. ${ }^{[21]}$ It is well tolerated and has no risk in the development of hyperchloremic acidosis. It should be used with caution in known hypersensitivity to Gelofusine as well as hypervolemia, severe cardiac insufficiency, renal impairment ${ }^{[3]}$ and because of the amount of sodium present (154mmols/litire) and hypernatremia. Gelofusine can, because of its osmotic effect, dilute the coagulation factors. ${ }^{[3]}$ However, it has also been linked with causing a coagulopathy because of its action on the cross linking of fibrin strands. Collagen in isolation can have a profound effect on the coagulation system; therefore collagen based colloids will exert the same effect however at a cellular level. The problem is that the conventional coagulation screen of APTT and INR are measuring clot formation at the thrombin stage. The effects of Gelofusine occur at the cellular stage which is after thrombin formation and as a result clot stability is not guaranteed. ${ }^{[22,23]}$

\section{Reflecting on future practice}

Reflecting on the empirical knowledge ${ }^{[24]}$ central to and used throughout the PGD development process, we concluded that reviewing the background pharmacology and completing the trusts pro-forma was integral in applying the pathophysiological principles of this clinical situation. We believed that the addition of this PGD to our current practice would demonstrate effective clinical reasoning as 
well as professional accountability in action. ${ }^{[25]}$ Moreover, it meant that patients no longer had to wait for the appropriate care to be provided and as a consequence their care was streamlined by ensuring that they receive the right care, at the right time and by the right person. ${ }^{[26,27]}$ However, we were always drawn back to the legal and ethical domain that governs their practice, ever mindful of the challenges to prove high levels of knowledge and competence as well as the professional considerations especially when using PGD's. ${ }^{[28,29]}$ For example those rooted in the nursing Code of Professional Conduct ${ }^{[30]}$ together with the Guidelines for the Administration of Medicines ${ }^{[31]}$ and the Royal College of Nursing's ${ }^{[25]}$ guidance for the use of PGD's. Yet when we compared this with our own individual personal knowledge ${ }^{[24]}$ we realised that experience and knowledgeable know-how, the technical-rationale paradigm, ${ }^{[32]}$ are not enough to ensure safe practice and the adherence to professional codes especially where the administration and the prescribing of prescription drugs are concerned. Indeed, this further reinforced aesthetically ${ }^{[24]}$ the way that we were able to identify the subtleties present in this patients condition that prompted our initial diagnosis, that tacit underpinning and recognition, articulation and integration of the whole. ${ }^{[24]}$

\section{Developing the PGD}

The initial difficulties in developing this PGD was the problem posed with having to liaise with so many specialty medical staff because of the sheer number of wards that Outreach had to cover. Trying to gain a consensus as to which patient groups, based on their particular consultant, this PGD would apply was almost impossible. The team was disappointed that it almost seemed that the idea was quashed before it started. Therefore our first step was to construct a domainal map of stakeholder influence so that the key people could be approached which could then create an open dialogue about our PGD's advantages and benefits to patient care (see Table 1).

Table 1: Domainal Map of Stakeholders ${ }^{[33]}$

\begin{tabular}{|c|c|c|c|}
\hline Stakeholders: & Ward Nursing Staff & Outreach Nursing Staff & Medical Staff \\
\hline $\begin{array}{l}\text { Present } \\
\text { Involvement: }\end{array}$ & Uncertainty of care required & - $\quad$ Hampered by care required & $\begin{array}{l}\text { Overall responsibility for } \\
\text { patient care activities }\end{array}$ \\
\hline Future Benefit: & $\begin{array}{ll}\text { - } & \text { Sense of involvement and } \\
\text { inclusivity } \\
\text { - } & \text { Continuity of care } \\
\text { - } & \text { Increased knowledge } \\
\text { - } & \text { Increased physical assessment } \\
\text { skills }\end{array}$ & $\begin{array}{ll}\text { - } & \text { Better inter-professional } \\
\text { - } & \text { Initiate appropriate treatment } \\
\text { - } & \text { More patient contact, } \\
\text { - } & \text { Direct and plan effective ward } \\
\text { based nursing care, } \\
\text { - } \quad \begin{array}{l}\text { Increased skills in teaching and } \\
\text { assessment. }\end{array}\end{array}$ & $\begin{array}{l}\text { Collaborative partnership in } \\
\text { the provision of care } \\
\text { More effective coordinated } \\
\text { services }\end{array}$ \\
\hline Potential Costs: & $\begin{array}{ll}\text { - } & \text { Increased assessment } \\
\text { - } & \text { Inappropriate referrals to } \\
\text { Outreach }\end{array}$ & Increased clinical responsibilities & $\begin{array}{l}\text { - } \quad \text { Preference for status quo } \\
\text { Loss of patient contact } \\
\text { decreased job satisfaction, and } \\
\text { training experiences for junior } \\
\text { doctors }\end{array}$ \\
\hline $\begin{array}{l}\text { Unaware } \\
\text { Wrecking Power: }\end{array}$ & $\begin{array}{l}\text { - } \quad \text { Resort to original patterns of } \\
\text { nursing care. }\end{array}$ & $\begin{array}{l}\text { - Ineffective inter-professional } \\
\text { communication, } \\
\text { - } \quad \text { Resort to original patterns of } \\
\text { nursing care. }\end{array}$ & $\begin{array}{l}\text { - } \quad \text { Lack of trust, } \\
\text { - } \quad \text { Interfere with planned care. }\end{array}$ \\
\hline
\end{tabular}

The work of Christensen and Christensen ${ }^{[34]}$ (2007) was integral in developing our domainal map as well as giving us insight into the process of transitional change theory. Therefore we also included in our PGD development a force field analysis $^{[35]}$ to serve as an adjunct to identifying the driving and resisting forces (see Table 2). We were fortunate enough to get support from the ICU consultants who were instrumental in mediating with medical colleagues under the guise that if patients were referred to Outreach then the ICU consultant 'on-call' for Outreach would be actively involved, collaboratively, in prescribing care. As such the need to confer with different medical teams was by and large dealt with by the ICU consultants and we were able to 'get-on' with the job at hand. However, following completion of the pro- forma, the time taken for approval was lengthy because of various amendments that needed to be rectified. The clinical governance team were meticulous in their appraisal of the PGD to the point that we felt that they were being too overly cautious without due consideration of those who would be applying the PGD. It was at this point that we nearly gave into perceived "gate-keeper" challenges because of what appeared to be unnecessary changes to our PGD. Yet in retrospect we could understand the governance teams caution and perhaps if we had identified prior to submission the potential challenges that we would have to face we could have planned better allowing a more amenable acceptance of our PGD, similar in some respects to that identified by our force field analysis (see Table 2). 
Table 2: Force-Field Analysis of PGD Development ${ }^{[35]}$

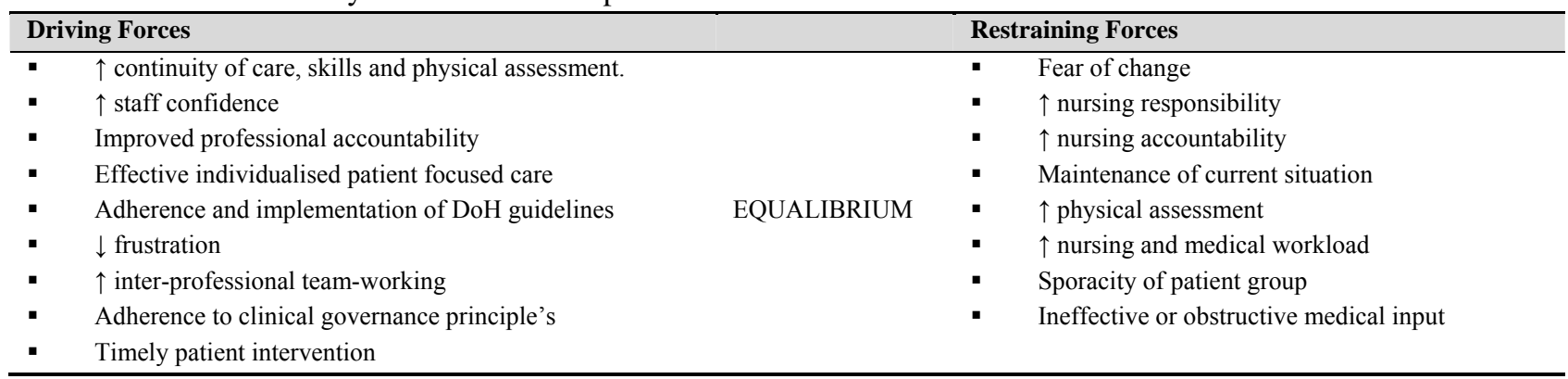

Table 3: Example of the PGD for Gelofusine administration by the Outreach Nursing team in the General Ward Environment

\begin{tabular}{|c|c|}
\hline \multicolumn{2}{|l|}{ CLINICAL CONDITION } \\
\hline Indication(s) & $\begin{array}{l}\text { - } \quad \text { Hypotension and /or oliguria } \\
\text { - } \quad \text { Evidence of poor perfusion (capillary refill time (CRT) greater than } 3 \text { seconds. }\end{array}$ \\
\hline Inclusion criteria & $\begin{array}{l}\text { Patients with: } \\
\text { - Hypotension - systolic blood pressure (BP) } 80-100 \mathrm{mmHg} \text {. } \\
\text { - } \quad \text { Oliguria - urine output less than } 1 / 2 \mathrm{ml} / \mathrm{kg} / \mathrm{hr} \text { for at least } 2 \text { hours. } \\
\text { - } \quad \text { Capillary refill greater than } 3 \text { seconds. }\end{array}$ \\
\hline Exclusion criteria & $\begin{array}{ll}\text { - } & \text { Avoid in anaphylaxis. } \\
\text { - } & \text { Known sensitivity to Gelofusine. }\end{array}$ \\
\hline Cautions/Need for further advice & - $\quad$ Patients exhibiting signs of cardiac failure, fluid overload, anaphylaxis. \\
\hline Action if patient declines or is excluded & $\begin{array}{l}\text { - } \text { Urgent referral to senior member of patient’s medical team or critical care medical staff. } \\
\text { - } \quad \text { Document in patient’s notes. } \\
\text { - } \quad \text { Give } 1 \text { litre Normal Saline } 0.9 \% \text { in anaphylaxis (according to PGD). }\end{array}$ \\
\hline \multicolumn{2}{|l|}{ DRUG DETAILS } \\
\hline Pharmaceutical Details & $\begin{array}{ll}- & \text { Name: Gelofusine } \\
\text { - } & \text { Form (tablet/mixture/injection etc.): Intravenous Infusion } \\
\text { - } & \text { Strength: } 4 \%\end{array}$ \\
\hline Route(s)/Method(s) of administration & Intravenous administration via peripheral or central line \\
\hline Dosage & $\begin{array}{l}\text { - } \quad 500-1000 \mathrm{mls} \text { to be administered over } 10 \text { minutes to } 1 \text { hour depending on patient's } \\
\text { condition and response to treatment. } \\
\text { - } \quad 200 \mathrm{mls} \text { only if cardiogenic shock is suspected }\end{array}$ \\
\hline Frequency & Maximum of 1 litre prior to each individual medical review. \\
\hline Duration of treatment & Up to 1 hour. \\
\hline OR Maximum or minimum treatment period & As above. \\
\hline Quantity to be supplied/administered & Up to 1 litre. \\
\hline Side effects & Anaphylaxis, increase in bleeding time (transient). \\
\hline Advice to patient/carer & $\begin{array}{l}\text { - } \quad \text { Explanation of reasons for fluid administration. } \\
\text { Acceptable limits of blood pressure (BP), pulse (P), urine output (UOP) and capillary } \\
\text { refill time (CRT). } \\
\text { - } \quad \text { Minimum monitoring requirements - CRT, P, BP, UOP. }\end{array}$ \\
\hline Follow-up & Urgent senior medical review regarding further fluid requirements and investigations. \\
\hline \multicolumn{2}{|l|}{ STAFF CHARACTERISTICS } \\
\hline Qualifications & - $\quad$ Registered Nurse RGN, RN(Adult) \\
\hline Specialist competencies or qualifications & $\begin{array}{l}\text { - } \quad \text { Minimum of } 2 \text { years' experience at senior nursing level (Grade Band } 5 \text { or above). } \\
\text { - } \quad \text { Acute Life Threatening Events Recognition and Treatment (ALERT) course } \\
\text { - } \quad \text { Relevant critical care post-registration course e.g. Advanced Life Support, Physical } \\
\text { Assessment, ENB } 100 .\end{array}$ \\
\hline Continuing training \& education & $\begin{array}{ll}\text { - } & \text { Annual life support update } \\
\text { - } & \text { Participation in ALERT course }\end{array}$ \\
\hline
\end{tabular}

Note. $\mathrm{ENB}=$ English National Board - a national UK accrediting authority for post-registration specialisation courses, in this case the ENB 100 is the Intensive Care Nursing Course. 
If the production of this PGD had not been undertaken then the consequences for patient care would be insurmountable, similar to those experienced by Robson et al ${ }^{[19]}$ Past experiences and data from the ongoing clinical audit of Outreach referrals of patients being admitted to ICU with acute fluid overload, hypovolemic shock, acute renal failure and acute respiratory failure secondary to pulmonary oedema are testament to the unstructured and inappropriate way that fluid management in the ward environment can sometimes occur. In some cases we felt helpless to intervene with admission to ICU the only available option. In our opinion the PGD for Gelofusine was a positive step forward if for anything to bring some uniformity to the way patients were cared for in terms of their fluid management (see Table 3).

\section{Implications for practice}

The introduction of a PGD for Gelofusine has improved the care the Outreach team can now provide. In the past we were reliant on medical decision-making which often meant delays in initiating treatment and in some cases inadvertent admission to the ICU for fluid management. This PGD has expanded, enlightened and re-examined the Outreach team's knowledge and ways of knowing and working. Firstly, it has expanded our personal knowledge not only of fluid management but also the legal and ethical premises that are in- volved in developing PGD's and the team's obligations and accountability whilst using them. Secondly it has stressed the importance of thoroughness and diligence in utilising the skills of conducting a physical examination especially of the cardio-respiratory system. Lastly, it has helped bridge the inter-professional relationships that we have with other health care professionals and as such will contribute to better future working relationships.

\section{Conclusion}

The process of developing a PGD for Gelofusine for use within the Outreach team was a rewarding experience. The current version is undergoing review in light of the changes to independent nursing prescribing ${ }^{[36,37]}$ in the UK and the way in which PGD's are used and developed. Whilst it is worthwhile acknowledging that this will contribute to an improvement in patient care, it is the innovative advancement in enhancing evidenced-based individualised patient centred care as well as reducing unnecessary admissions to ICU that matters as well.

\section{Conflicts of Interest Disclosure}

The author declares that there is no conflict of interest statement.

\section{References}

[1] Department Of Health. Comprehensive Critical Care: A Review of Adult Critical Care Services. London, Department of Health. 2000.

[2] Dougherty, L., Lister, S. The Royal Marsden Hospital Manual of Clinical Nursing Procedures, 8th ed. London, Wiley. 2011.

[3] British National Formulary. British National Formulary. London: British Medical Association and Royal Pharmaceutical Society of Great Britain. 2007.

[4] Dawson, D. Extension of nurse prescribing - is there a case for nurse prescribing in critical care? Intensive \& Critical Care Nursing. 2001; 17: 315-317. PMID:11853006 http://dx.doi.org/10.1054/i ccn.2000.1563

[5] Her Majesty's Stationary Office. Medicines Act 1968. London, Her Majesty's Stationary Office. 1968.

[6] Department Of Health and Social Service. Neighbourhood Nursing: A Focus for Care. (Cumberlege Report). London: Her Majesty's Stationary Office. 1986.

[7] Department Of Health, 1989. Report of the Advisory Group on Nurse Prescribing (Crown Report). London: Her Majesty's Stationary Office.

[8] Her Majesty's Stationary Office. Medicinal Products: Prescription by Nurses etc. Act 1992. London, Her Majesty's Stationary Office. 1992.

[9] Department Of Health. Review of Prescribing, Supplying and Administration of Medicine. A report on the supplying and administration of medicines under group protocols. London: Department of Health. 1998.

[10] Department Of Health. Health Service Circular, Patient Group Directions [England Only]. London: NHS Executive Department of Health, HSC 2000/026. 2000.
[11] Baird, A., Morgan, J. Developing a patient group direction for use in primary care. Primary Health Care. 2000; 11(1): 21-24. http://dx.doi.org/10.7748/phc2001.02.11.1.21.c281

[12] National Prescribing Centre. Patient Group Directions: A Practical Guide and Framework of Competencies for all Professional using Patient Group Directions. London, National Prescribing Centre. 2004.

[13] The Stationary Office. The Human Medicines Regulations 2012. London, The Stationary Office, 2012.

[14] National Institute for Health and Care Excellence. Patient Group Directions. London, NICE. 2014.

[15] McCormick, C. Midwives and patient group directions: supplying medicine. British Journal of Midwifery. 2002; 10(5): 286-287. http://dx.doi.org/10.12968/bjom.2002 .10.5.12314

[16] Price, O., Baker, J. Resistance to changing practice from pro re nata prescriptions to patient group directions in acute mental health settings. Journal of Psychiatric and Mental Health Nursing. 2013; 20(7): 623-630. PMID:22957970 http://dx.doi.org/10.1111 $/ j .1365-2850.2012 .01960 . x$

[17] Black, A., Dawood, M. A comparison in independent nurse prescribing and patient group directions by nurse practitioners in the emergency department: a cross sectional review. International Emergency Nursing. 2014; 22(1): 10-17. PMID:23648174 http://dx.d oi.org/10.1016/j.ienj.2013.03.009

[18] Price, O., Baker, J., Paton, C., Barnes, T. Patient group directions: a safe and effective practice. British Journal of Nursing. 2012; 21(1): 26-31. PMID:22240517 http://dx.doi.org/10.12968/ bjon.2012.21.1.26

[19] Robson, W.P., Webster, S., Blakemore, K., et al. The use of patient group direction to ensure prompt treatment of postoperative hypotension in orthopaedic patients. Journal of Orthopaedic Nurs- 
ing. 2003; 7(4): 197-200. http://dx.doi.org/10.1016/j.joo n.2003.09.003

[20] Guyton, A.C., Hall, J.E. Textbook of Medical Physiology 12th ed. New York, Saunders. 2011.

[21] B/Braun Melsungen AG. Gelofusine: modified fluid gelatine. Melsungen, B/Braun. 2005.

[22] Brazil, E.V., Coats, T.J. Sonoclot coagulation analysis of in-vitro haemodilution with resuscitation fluids. Journal of the Royal Society of Medicine. 2000; 93: 507-510. PMID:11064686

[23] Coats, T.J., Heron, M. Does calcium cause the different effects of Gelofusine and Haemaccel on coqagulation? British Medical Journal. 2006; 23: 193-194.

[24] Carper, B.A. Fundamental patterns of knowing in nursing. Advances in Nursing Science. 1978; 1(1): 13-23. http://dx.doi.org/10. 1097/00012272-197810000-00004

[25] Royal College Of Nursing. Patient Group Directions: Guidance and Information for Nurses. London, Royal College of Nursing. 2006.

[26] Miles, K., Penny, N., MacDougal, H. Patient group directions in nurse-led sexual health clinics. Nursing Standard. 2001; 16(7): $33-$ 34. PMID:11974825 http://dx.doi.org/10.7748/ns2001.10 .16 .7 .33$. c3108

[27] Spyropoulos, A. Patient group directions. Nursing Times. 2002; 98(9): 48. PMID:11917395

[28] Dimond, B. Patient group directions to enable hospital nurses to supply medicines. British Journal of Nursing. 2003; 12(14): 880883. PMID:12951540 http://dx.doi.org/10.12968/bjon.2 003.12 .14 .11406
[29] Griffith, R. Medicines and the law - patient group directions. British Journal of Midwifery. 2009; 17(7): 460-461. http://dx.doi .org /10.12968/bjom.2009.17.7.43065

[30] Nursing \& Midwifery Council. The NMC Code of Professional Conduct: standards for conduct, performance and ethics. London, Nursing and Midwifery Council. 2008.

[31] Nursing \& Midwifery Council. Guidelines for the Administration of Medicines. London, Nursing and Midwifery Council. 2008.

[32] Schon, D., 1990. Educating the reflective practitioner: toward a new design for teaching and learning in the professions. London, Wiley.

[33] Spiegal, N., Murphy, E., Kinmonth, A.L., Ross, F., Bain, J., Coates, R. Managing change in general practice: a step by step guide. British Medical Journal. 1992; 304(6821): 231-234. PMID:1739799 http://dx.doi.org/10.1136/bmj.304.6821.231

[34] Christensen, T., Christensen, M. The implementation of a guideline of care for patients with a Sengstaken-Blakemore tube insitu in a general intensive care unit using transitional change theory. Intensive and Critical Care Nursing. 2007; 23(4): 234242. PMID:17434309 http://dx.doi.org/10.1016/j.iccn. 2006.05 .004

[35] Lewin, K. Field Theory in Social Science. New York, Harper. 1951.

[36] Department of Health. Improving patients' access to medicines: a guide to implementing nurse and pharmacist independent prescribing within the NHS in England. London, Department of Health. 2006.

[37] Department Of Health. Nurse Independent Prescribing. London: Department of Health. 2006. 